\title{
OSEBNI ZAIMKI V FUNKCIJI OSEBKA: PRAGMATIČNI VIDIKI SLOVNIČNE KATEGORIJE
}

\author{
Agnes PISANSKI PETERLIN
}

Filozofska fakulteta Univerze v Ljubljani

\section{Tamara MIKOLIČ JUŽNIČ}

Filozofska fakulteta Univerze v Ljubljani

Pisanski Peterlin, A., Mikolič Južnič, T. (2018): Osebni zaimki v funkciji osebka: pragmatični vidiki slounične kategorije. Slovenščina 2.o, 6 (2): 127-153.

DOI: http://dx.doi.org/10.4312/slo2.0.2018.2.127-153.

S korpusno analizo je mogoče pridobiti relevantne podatke o slovničnih pojavih, na podlagi katerih se lahko oblikujejo poglobljeni slovnični opisi. Korpusna metodologija je posebej uporabna za slovnične raziskave, ki se osredotočajo na pragmatiko in variacije v rabi izbranih slovničnih elementov. Namen pričujoče raziskave je analizirati rabo osebnih zaimkov v funkciji osebka v slovenščini s pragmatičnega vidika in tako pridobiti nove podatke za bolj podroben opis rabe osebnega zaimka kot osebka v slovenščini. Slovenščina je jezik z opustljivim osebkom, kar pomeni, da osebka stavka v njej ni treba eksplicitno izraziti. Raziskava temelji na korpusni analizi korpusov Kres in Gos; narejena je bila s pomočjo spletne programske aplikacije za analizo besedil NoSketch Engine. Rezultati pokažejo precejšnjo razliko v pogostosti rabe osebnih zaimkov kot osebkov med govornim in pisnim diskurzom. Rezultati prav tako pokažejo, da število osebnih zaimkov upada z naraščanjem formalnosti. N podlagi funkcijske analize so izraženi osebni zaimki v najširšem smislu klasificirani v kategoriji razdvoumljanja in poudarjanja. $\mathrm{V}$ okviru razdvoumljanja na rabo osebnih zaimkov kot osebkov vplivajo oblikoslovni, skladenjski in diskurzni dejavniki, in tudi prenosnik. V kategoriji poudarjanja je prenosnik posebej relevanten dejavnik. Analiza pokaže, da je tematika osebnega zaimka kot osebka v slovenščini mnogo kompleksnejša, kot bi lahko sklepali iz dosedanjih opisov. Izsledki raziskave odpirajo nekatera zanimiva vprašanja glede rabe osebnega zaimka kot osebka v slovenščini v zvezi z dialektalno specifiko in v hibridnih 
internetnih žanrih, prav tako pa tudi vprašanja o vplivu lektorskih posegov in o vplivu usvajanja pismenosti.

Ključne besede: osebni zaimek kot osebek, jezik z opustljivim osebkom, korpusna analiza

\section{UVOD}

Uporaba korpusnega pristopa za raziskave slovničnih pojavov predstavlja odmik od tradicionalnih raziskav slovnične problematike, ki so vir za slovnične opise jezikovnega sistema (gl. tudi Krek 2013). Kot opozarja Susan Conrad (2010: 227) tradicionalne raziskave slovničnih pojavov, ki ne izhajajo iz analize rabe jezika (ki jo je mogoče opazovati na korpusnem gradivu) navadno temeljijo na razlikovanju med slovnično pravilnimi ali nepravilnimi primeri. Conrad (ibid.) poudarja, da je tak tradicionalni pristop, osnovan na dihotomiji ustrezno-neustrezno, uporaben za opise nekaterih slovničnih elementov, ne pa vseh: pri nekaterih slovničnih kategorijah je mogoče opazovati več variacij glede na različne sociolingvistične in funkcijske spremenljivke. Conrad (2010: 228) tako kot prispevek korpusnega jezikoslovja k opisom slovnice navaja zlasti to, da korpusni pristop omogoča proučevanje velikih zbirk besedil, v katerih je mogoče opazovati tipične in netipične vzorce v različnih kontekstih. Lahko bi torej povzeli, da je korpusni pristop posebej uporaben za slovnične raziskave, ki se osredotočajo na pragmatiko in variacije $\mathrm{v}$ rabi izbranih slovničnih elementov, seveda pa je treba vedno upoštevati tudi sestavo in vrsto korpusa.

Primer slovničnega problema, ki ga ni mogoče opisati z dihotomijo ustreznoneustrezno $\mathrm{v}$ slovenskem jeziku predstavlja raba osebnega zaimka $\mathrm{v}$ funkciji osebka. V slovenščini kot v mnogih drugih jezikih osebka glavnega stavka ni treba eksplicitno izraziti (prim. tudi Golden 1996: 171, Toporišič 2000: 307); osebka torej ni treba še dodatno zaimkovno opredeljevati, ker je v večini primerov izražen $\mathrm{v}$ končnici osebnih glagolskih oblik. Jeziki z opustljivim osebkom (izraz je povzet po Golden 1996: 261) so bili podrobno analizirani v sklopu tvorbeno-pretvorbenega jezikoslovja (prim. npr. Jaeggli \& Safir 1989), 
raziskave tega pojava pa segajo prek okvirov teoretičnega jezikoslovja: razlikovanje med jeziki z opustljivim in obveznim osebkom je posebej zanimivo z vidika stika med jeziki, npr. usvajanje tujega jezika (npr. Tsimpli in sod. 2004, Sorace in Filiaci 2006), dvojezičnosti (npr. Paradis in Navarro 2003, Serratrice 2007) in prevajanja (npr. Mauranen 2005, Baroni in Bernardini 2006).

Prav študije medjezikovnih razlik in medsebojnih vplivov jezikov so pokazale, da je tudi med jeziki z opustljivim osebkom mogoče razlikovati različne podtipe (prim. tudi klasifikacijo, ki jo navajata Roberts in Holmberg 2010: 5-13) v okviru katere se slovenščina, podobno kot npr. italijanščina, španščina in sodobna grščina, uvršča $\mathrm{v}$ kategorijo jezikov $\mathrm{s}$ konsistentno opustljivim osebkom, ki so zaenkrat najbolj raziskana kategorija jezikov z opustljivimi osebki (Roberts in Holmberg 2010: 6)). Vendar so podrobnejše analize pokazale, da je celo znotraj posameznih podtipov jezikov mogoče opazovati razlike, znotraj posameznih jezikov pa dialektalne mikrovariacije (prim. npr. Sorace in Filiaci 2006). Za slovenščino je primerjava slovenskih in italijanskih zaimkov v funkciji osebka (Pisanski Peterlin in Mikolič Južnič 2018) pokazala velike razlike v pogostosti rabe med jezikoma, kar je precej presenetljivo, saj jezika sicer sodita $\mathrm{v}$ isti podtip jezikov $\mathrm{z}$ opustljivim osebkom. Na podlagi izsledkov omenjene raziskave je mogoče za slovenščino sklepati o zelo specifični rabi osebnih zaimkov v funkciji osebka, ki je v primerjavi z nekaterimi drugimi jeziki z opustljivim osebkom, bolj omejena.

V opisu rabe osebnega zaimka kot osebka v slovenščini v Slovenski slovnici (Toporišič 2000: 307) je navedeno, da se v slovenščini osebni zaimek v imenovalniku uporablja v specifičnih situacijah: v odgovoru na vprašanja po glagolski osebi (npr. kot odgovor na vprašanje, ki se začne s $k d o$ ), če je glagolska oseba eden izmed delov priredno sestavljenega dela povedi (npr. vi in jaz), če ima glagolska oseba še kakšna določila (Toporišič (ibid.) navaja primer Jaz, knez modruški...), kadar glagolska oseba iz povedka in sobesedila ni razvidna (npr. pogojnik v ednini), če hočemo podati ozračje domačnosti (navedenih je nekaj primerov iz neformalnega govora) in če se hoče vzpostaviti kontrast 
(Toporišič (ibid.) navaja primer Jaz grem na delo in argumentira, da je jaz v takem stavku smiseln le v primeru, kadar želimo "povedati, da pa za druge ne ve, kam gredo«). O močni tendenci opuščanja osebnega zaimka kot osebka v knjižnem jeziku priča tudi opažanje, ki je navedeno v Koletnik (2008: 39), in sicer, da se v prekmurskem narečju pojavlja osebni zaimek, kjer je v knjižni slovenščini pričakovan »ničti zaimek«. Podobno bi lahko tudi izpostavili možnost nadomeščanja osebnega zaimka s kazalnim ali z zaimkom sam (prim. Pisanski Peterlin in Mikolič Južnič 2018: 242). K temu velja dodati, da se osebni zaimki v imenovalniku v slovenščini navadno lahko nanašajo le na žive osebke: posebnih raziskav na temo rabe zaimkov v imenovalniku za nežive osebke sicer še ni bilo, zdi pa se, da je takšna raba redka in zaznamovana.

Namen pričujoče raziskave je analizirati rabo osebnih zaimkov v funkciji osebka $\mathrm{v}$ slovenščini s pragmatičnega vidika in tako nadgraditi obstoječe slovnične opise. Na podlagi korpusne analize korpusov Kres (http://www.korpuskres.net/) in Gos (http://www.korpus-gos.net/) so osebni zaimki v funkciji osebka razčlenjeni z žanrskega in diskurzno-pragmatičnega vidika.

\section{IZRAŽANJE OSEBKA KOT DISKURZNO-PRAGMATIČNO SREDSTVO}

Referenca kot oblika slovnične kohezije se izraža skozi kazalne in osebne zaimke (za podrobnejši pregled koncepta za slovenščino, prim. Korošec (1981) in Gorjanc (1999)). Gorjanc (1999: 141) poudari, da je pogoj za referenčnost v besedilu prisotnost nanašalnice in naveznika/napovednika, ki znotraj besedila vzpostavljata koreferenčno besedilno vez. Serratrice (2007:1058-9) izpostavi dejstvo, da je funkcija jezikovnih elementov, ki vzpostavljajo referenčno kohezijo, označevanje informacije o nekem elementu v smislu razlikovanja med znanim in novim.

Uporaba osebnih zaimkov kot kohezijskih sredstev se med jeziki razlikuje. V jezikih z obveznim osebkom se razlikovanje med novimi in starimi informacijami odraža skozi pronominalizacijo (Paradis and Navarro 2003:375); v teh jezikih se nove informacije vpeljejo s samostalniško besedno 
zvezo, stare informacije pa se izrazijo z zaimkom. Po drugi strani pa se v jezikih z opustljivim osebkom razlikovanje med novimi in starimi informacijami odraža skozi izražen ali opuščen osebek. V teh jezikih se osebni zaimek kot osebek pojavlja ob tematskih premikih, da bi se izognili referenčni dvoumnosti, in na mestih, kjer uvajajo kontrast ali poudarek (prim. Paradis and Navarro 2003; Rothman 2009). Serratrice (2007) v svoji študiji referenčne kohezije v pripovedih angleško-italijansko dvojezičnih otrok poudari razliko med vzdrževanjem in ponovno vpeljavo nanašalnice: $v$ jezikih z opustljivim osebkom osebek ni eksplicitno izražen, kadar se $\mathrm{v}$ dveh zaporednih stavkih ohranja ista tema, kadar pa pride do tematskega premika, se uporabi osebni zaimek kot osebek.

Vendar pa nekatere druge raziskave jezikov z opustljivim osebkom kažejo, da poleg opisanih diskurzno-pragmatičnih dejavnikov na odločitev za opustitev osebka vpliva lahko še vrsta drugih dejavnikov. V literaturi se tako kot drugi potencialni dejavniki, ki vplivajo na rabo osebnih zaimkov, omenjajo žanr oziroma vrsta diskurza v širšem smislu (Travis (2007) ugotavlja občutne razlike med monološko pripovedjo in dialoškim pogovorom), referent slovnične osebe (Posio (2012) pokaže, da je v evropski španščini in portugalščini mogoče opazovati različno pogosto rabo osebnega zaimka kot osebka med inkluzivno in ekskluzivno prvo osebo ednine) in dialektalna specifika (Paradis and Navarro (2003: 375) navajata izrazito specifiko karibske španščine v primerjavi drugimi španskimi dialekti). V tem kontekstu velja omeniti, da tudi za slovenščino Koletnik (2008: 39) opozori na dialektalno specifiko rabe osebnega zaimka kot osebka pri upovedovanju prekmurskega narečja, kjer prihaja do odstopanja od knjižne norme, pri čemer $\mathrm{v}$ prispevku narava knjižne norme ni nadalje pojasnjena. Očitno je torej, da je raba osebka v jezikih z opustljivim osebkom kompleksno vprašanje in zahteva večplastni opis. Zato predstavlja vsak poskus, da bi se pri opisu omejili na en sam dejavnik, poenostavitev, ki je v nekaterih primerih morda uporabna, v raziskavi, kot je pričujoča, katere namen je nadgraditi obstoječe razumevanje tega pojava v slovenščini, pa seveda ni. 
Na podlagi pregleda literature se postavlja vprašanje, ali je s korpusno analizo dejanske rabe osebnega zaimka $\mathrm{v}$ slovenščini mogoče pridobiti natančnejše podatke o pragmatičnih vidikih izražanja in opuščanja osebka v slovenščini. Konkretno želiva $\mathrm{v}$ pričujoči študiji odgovoriti na naslednji raziskovalni vprašanji:

1) Ali je pogostost rabe osebnih zaimkov kot osebkov pogojena $\mathrm{z}$ besedilno zvrstjo?

2) Kateri dejavniki vplivajo na rabo osebnih zaimkov kot osebkov?

\section{KORPUS IN METODA}

\subsection{Korpus}

V analizi bila sta uporabljena korpusa Kres in Gos, ki sta nastala v okviru projekta Sporazumevanje $v$ slovenskem jeziku; za več podrobnosti o korpusu Kres gl. npr. Logar in sod. (2012), za več podrobnostih o korpusu Gos gl. Verdonik in Zwitter Vitez (2011), za več podrobnosti o samem projektu pa projektni spletni portal (www.slovenščina.eu). Korpus Kres je uravnoteženi pisni korpus slovenskega jezika, ki po podatkih $\mathrm{z}$ omenjenega portala obsega 99.831.145 besed v besedilih, ki so izšla med letoma 1990 in $2011^{1}$ (prim. tudi Erjavec in Logar Berginc 2012), korpus Gos pa je govorni korpus slovenskega jezika, ki obsega 1.035.101 besedo (prim. tudi Verdonik in sod. 2013). ${ }^{2}$

Za korpusno analizo je uporabljen korpus Gos v celoti. Korpus Gos omogoča iskanje po štirih sklopih oziroma podkorpusih (Verdonik in sod. 2013), ki so ločeni po besedilnovrstnih kriterijih, in sicer: javni informativno-izobraževalni govor (informativni medijski diskurz ter pedagoški diskurz v osebnem stiku), javni razvedrilni (medijski diskurz), nejavni nezasebni (telefonski in osebni pogovori v uradih, trgovinah, itd.) in nejavni zasebni (telefonski in osebni

\footnotetext{
${ }^{1}$ Omeniti velja, da je velik delež besedil v korpusu Kres lektoriran, saj gre za objavljena literarna, neliterarna in medijska besedila.

${ }_{2}^{2}$ Podatki o obsegu korpusov so bili veljavni v času, ko je bila narejena analiza (julij 2016).
} 
pogovori v družini in med prijatelji).

Korpus Kres za korpusno analizo ni bil uporabljen povsem v celoti, čeprav je bila analizirana velika večina korpusa (v skupnem obsegu 85.993.551 besed), kar predstavlja več kot $85 \%$ celotnega korpusa Kres. Za primerjavo med besedilnimi zvrstmi je bilo namreč smiselno zagotoviti čim večjo žanrsko in registrsko homogenost posameznih zvrsti. Tako so bili uporabljeni naslednji sklopi besedil iz korpusa Kres:3 leposlovje, revije, časopisi, stvarna besedila brez podkategorije »drugo « in besedil Zavoda za šolstvo (za zagotovitev čim večje homogenosti) in internetna besedila brez transkriptov iz Državnega zbora (zaradi hibridne narave besedil), ne pa tudi kategorija »drugo «, ki je bila preveč heterogena za smiselno uporabo. $V$ pričujoči raziskavi so tako rezultati analize korpusa Kres združeni v naslednjih podkorpusih, glede na besedilno zvrst: leposlovje, periodika (obsega sklopa časopisi in revije), strokovna besedila (obsega poljudnoznanstvena in strokovna neliterarna besedila $\mathrm{v}$ sklopu stvarnih besedil) in internetna besedila (obsega novičarske portale s komentarji in spletne strani podjetij).

\subsection{Metoda}

V prvi fazi analize so bile s pomočjo spletne programske aplikacije NoSketch Engine (http://nl.ijs.si/noske/index.html) identificirane vse pojavitve osebnih zaimkov v imenovalniku v vseh podkorpusih, zajetih v analizi. Iskalni parametri so obsegali besedno vrsto »osebni zaimek « in sklon »imenovalnik «, 4 zato je bilo pri večini zaimkov šuma, torej primerov, ko ni šlo za osebne zaimke v imenovalniku, izjemno malo.

Nekoliko več šuma se je pojavilo pri zaimkih ona, ono in oni zaradi homonimije

\footnotetext{
3 Zaradi doslednosti opisa metode dela, preciznosti rezultatov in omogočanja ponovljivosti se pri kategorizaciji korpusa Kres ne sklicujeva na teoretično klasifikacijo v Logar in sod. (2012) temveč na kategorizacijo, ki izhaja iz strani spletnega konkordančnika korpusa Kres (http://www.korpus-kres.net/).

4 Zaradi narave korpusnega iskanja, ki izhaja iz oblikoskladenjske označenosti uporabljenih korpusov, je bilo med zadetki nekaj primerov imenovalnikov, ki niso bili uporabljeni v vlogi osebka temveč npr. povedkovega določila, ki so bili iz kvalitativne analize izločeni.
} 
s kazalnim zaimkom oni. Pri zaimkih ona in oni je bilo na podlagi pregleda 900 primerov ocenjeno, da je šuma še vedno malo (v nobenem podkorpusu ne več kot $10 \%$, v nekaterih tudi občutno manj), zato so pri teh dveh zaimkih navedene številke vseh zadetkov. Za zaimek ono pa so bili vsi rezultati prečiščeni ročno, saj je bilo skupno število zadetkov zelo nizko.

Za osebne zaimke $t i, m i$, me in ve je prvo iskanje pokazalo, da se med rezultati pojavlja veliko šuma, ki je posledica homonimij s kazalnim zaimkom ta, dajalnikom in tožilnikom osebnega zaimka jaz in tretjo osebo ednine glagola vedeti, zato je bilo za te zaimke opravljeno natančnejše iskanje, in sicer na podlagi iskalnih kriterijev besedna vrsta »osebni zaimek«, sklon »imenovalnik«, bližina glagola v ustreznem številu in osebi (oddaljenost do 5 besed) in dodatno pri ti izločitev zadetkov, ki se nahajajo neposredno pred samostalnikom (in lahko tudi pridevnikom in samostalnikom) $\mathrm{v}$ imenovalniku (za izločitev kazalnega zaimka).

Rezultati so bili nato izraženi v obliki števila pojavitev na 1.000 besed, kar je omogočalo natančnejšo primerjavo pogostosti med posameznimi vrstami diskurza. 5

V drugi fazi analize so bili ročno pregledani naključno vzorčeni seznami zadetkov za vsak zaimek posebej, in sicer po 50 zadetkov za vsak sklop besedil ali manj, kjer je bilo skupno število zadetkov v sklopu manjše od 50. Skupno je to pomenilo pregled 450 zadetkov za vsak zaimek, oz. nekoliko manj v primerih, kjer je bilo število zadetkov manjše od 50 . Vsak primer je bil klasificiran glede na rabo. Osnovna delitev na kategoriji razdvoumljanje in poudarek je izhajala iz literature (prim. razdelek 2) in zlasti iz prejšnje raziskave rabe osebnih zaimkov za slovenščino in italijanščino (prim. Pisanski Peterlin in Mikolič

\footnotetext{
$5 \mathrm{~V}$ pričujočem prispevku je termin diskurz rabljen v smislu ravni jezika nad ravnijo povedi in ne le v smislu govorjenega jezika. Termin »diskurz« je namreč na področju diskurznopragmatičnih študij zaimkov $\mathrm{v}$ jezikih $\mathrm{z}$ opustljivim osebkom dobro uveljavljen in ga ni mogoče preprosto nadomestiti, saj omogoča osredotočanje na vprašanje jezika v rabi (za natančnejši opis kompleksnosti termina diskurz v uporabnem jezikoslovju prim. npr. Hyland in Paltridge (2011:1)).
} 
Južnič 2018), kjer se je delitev izkazala za učinkovito; dodatne podkategorije so izhajale iz korpusne analize.

\section{REZULTATI IN DISKUSIJA}

V nadaljevanju so ločeno predstavljeni in razčlenjeni kvantitativni rezultati (razdelek 4.1) in kvalitativni izsledki analize (razdelek 4.2)

\subsection{Pogostost rabe osebnih zaimkov kot osebkov}

Povprečna pogostost pojavitev osebnih zaimkov kot osebkov v celotnem analiziranem gradivu je 1,7 pojavitev na 1000 besed. Na Sliki 1 so v obliki stolpčnega grafa predstavljeni podatki o pogostosti rabe osebnih zaimkov kot osebkov na 1000 besed v analiziranih podkorpusih besedil korpusov Gos in Kres glede na besedilno zvrst.

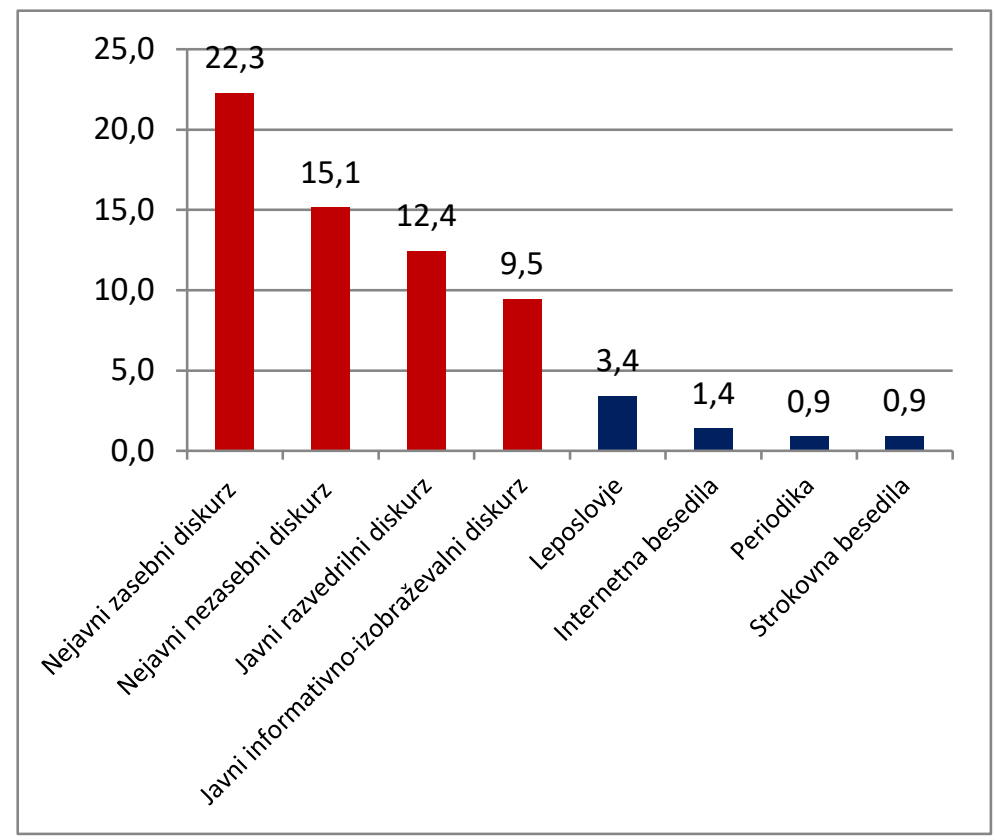

Slika 1: Pogostost rabe osebnih zaimkov kot osebkov v posameznih podkorpusih: število pojavitev na 1000 besed. 


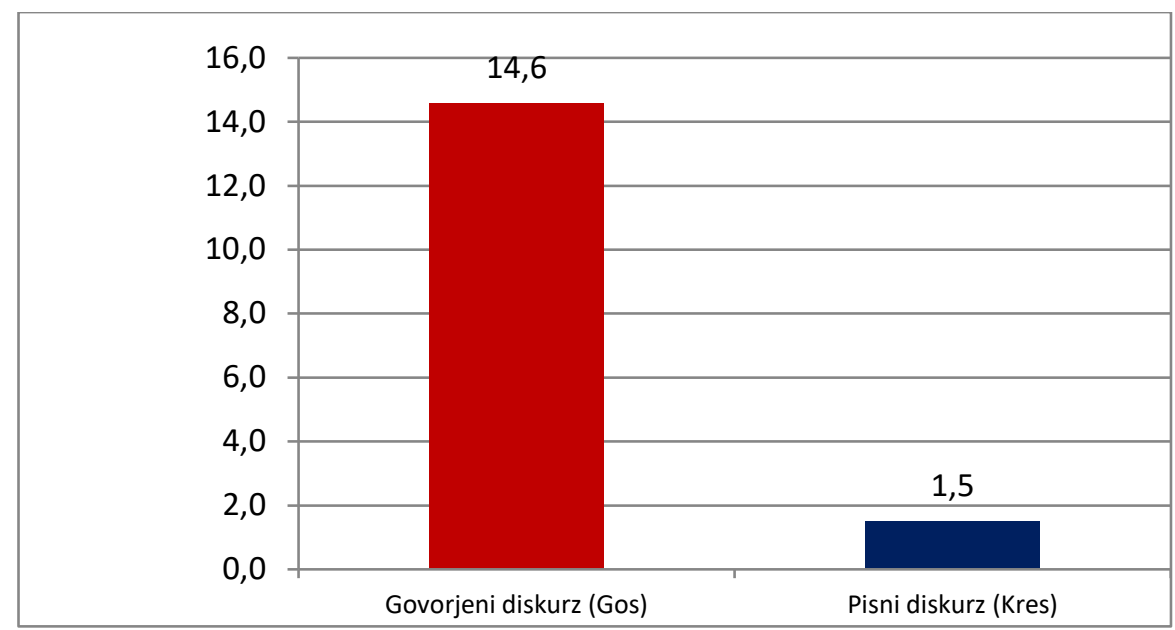

Slika 2: Primerjava pogostosti rabe osebnih zaimkov kot osebkov v govorjenem in pisnem diskurzu: število pojavitev na 1000 besed.

Primerjava podatkov presenetljivo jasno pokaže, da se raba osebnega zaimka kot osebka v slovenščini v različnih zvrsteh močno razlikuje. Če kot kriterij za razvrstitev zvrsti upoštevamo formalnost, ${ }^{6}$ je za govorjeni diskurz smiselno privzeti, da je nejavni zasebni diskurz (npr. pogovor med prijatelji ali družinskim članki) nekoliko manj formalen od nejavnega nezasebnega diskurza (npr. pogovor v uradu), pa tudi da je javni razvedrilni diskurz, ki se pojavlja v medijih (npr. razvedrilna oddaja) sicer bolj formalen od nejavnega diskurza, a manj formalen od javnega informativnega diskurza (npr. informativna oddaja). Podobno je mogoče za pisni diskurz privzeti, da je v leposlovju (npr. dialog) in internetnih besedilih (npr. spletni komentar) mogoče pričakovati več elementov, ki so tipični za spontani govor in manj formalni, kot v stvarnih

\footnotetext{
${ }^{6}$ Termin formalnost je v prispevku rabljen $\mathrm{v}$ uveljavljenem jezikoslovnem smislu, povzemava pa še slovarsko definicijo, ki jo navaja Crystal (1992: 142), kjer je formalnost opisana kot »dimenzija družbenega vedenja«, pri kateri se stopnja regulacije odraža skozi različne jezikovne lastnosti. Visoka stopnja formalnosti jezika pomeni zelo skrbno organiziran diskurz, pogosto tudi kompleksno skladnjo in besedišče, ki v veliki meri sledi standardnemu jeziku. Visoka stopnja neformalnosti se v jeziku odraža skozi ohlapno strukturiranje, številne pogovorne izraze in pogosto odstopa od standarda (npr. skozi rabo slenga, dialektalnih izrazov, neologizmov itd.).

(opomba se nadaljuje na naslednji strani)
} 
besedilih in v periodiki. Čeprav za gradivo, uporabljeno v pričujoči analizi, velja, da so zvrsti, ki sestavljajo oba korpusa, razmeroma heterogene, je prav tako smiselno privzeti, da je govorjeni diskurz na splošno manj formalen od pisnega: ${ }^{7}$ za večji del analiziranega govorjenega diskurza je mogoče ugotavljati, da je tvorjen bolj ali manj spontano in vsebuje več neformalnih elementov, za večino analiziranega pisnega diskurza pa velja, da gre za besedila, ki so načrtovana, revidirana in objavljena. Pomembno odstopanje od te na prvi pogled jasne delitve predstavljata javni informativni diskurz, ki je večinoma $\mathrm{v}$ naprej pripravljen, revidiran in bran, in internetni komentarji, ki so večinoma zelo spontano tvorjeni in se približujejo spontanemu govoru. A ker podkorpus javni informativno-izobraževalni govor vsebuje tudi pedagoški govor $\mathrm{v}$ osebnem stiku, ki je tudi spontano tvorjen, internetna besedila pa tudi medijske vsebine z novičarskih portalov, ki so načrtovana in revidirana, ni mogoče trditi, da ta dva podkorpusa $\mathrm{v}$ celoti odstopata od ostalih govorjeni in pisnih besedil $\mathrm{v}$ smislu formalnosti.

Če torej sprejmemo tezo, da je mogoče podkorpuse razvrstiti glede na formalnost, je iz Slike 1 razvidno, da število osebnih zaimkov v analiziranem gradivu izrazito upada z naraščanjem formalnosti posamezne vrste diskurza. $\mathrm{V}$ govorjenem diskurzu (korpusu Gos) je tako raba osebnih zaimkov skoraj desetkrat pogostejša kot v pisnem (korpusu Kres): razmerje je 14,6 pojavitev proti 1,5 pojavitev na 1000 besed (prim. Sliko 2). Podatki na Sliki 1 jasno pokažejo, da je v govorjenih vrstah diskurza mogoče opazovati razlike med nejavnim in javnim diskurzom, pri čemer je v nejavnem diskurzu raba osebnih zaimkov pogostejša, in sicer je najpogostejša $\mathrm{v}$ zasebnem diskurzu

\footnotetext{
7 Jasno je, da so razlike med govorjenim in pisnim jezikom kompleksne in ne zadevajo le stopnje formalnosti, temveč celo vrsto dejavnikov, od neposrednega stika med tvorcem in naslovnikom, neverbalnih elementov, ki so prisotni v komunikaciji (gestikulacija in mimika proti grafičnim elementom), stopnje dialoškosti oziroma monološkosti, spontanosti, vnaprejšnje priprave, prostorskega in časovnega stika, in še bi lahko naštevali. Nekateri od omenjenih dejavnikov gotovo lahko do neke mere vplivajo na rabo osebnih zaimkov kot osebkov in so $\mathrm{v}$ analizi tudi obravnavani (neposredni nagovor $\mathrm{v}$ dialogu, netekočnost $\mathrm{v}$ spontanem govoru).
} 
(22,3 pojavitve na 1000 besed), torej v neformalni, spontani, sproščeni osebni ali telefonski komunikaciji med sorodniki, prijatelji in znanci, nekoliko manj pogosta pa je v polformalnih situacijah nezasebnega diskurza (15,1 pojavitve na 1000 besed), torej v osebni ali telefonski komunikaciji v trgovini, v uradu, $\mathrm{v}$ pisarni (za natančnejši opis vrst diskurza v Gosu prim. Verdonik in Zwitter Vitez 2011). V javnem diskurzu - v veliki meri gre za medijski diskurz, pri katerem je stopnja formalnosti višja - je raba osebnih zaimkov kot osebkov v primerjavi z nejavnim diskurzom nekoliko manj pogosta: znova je mogoče zaznati razlike med razvedrilnim diskurzom (12,4 pojavitve na 1000 besed), v katerem je osebnih zaimkov kot osebkov več, v primerjavi z bolj formalnim informativnoizobraževalnim diskurzom, $\mathrm{v}$ katerem je zaimkov manj (9,5 pojavitve na 1000 besed).

V pisnih vrstah diskurza je raba osebnih zaimkov kot osebkov izrazito redka; skupno je v analiziranih delih Kresa v povprečju 1,5 pojavitve osebnih zaimkov kot osebkov na 1000 besed (prim. Sliko 2). Kot je razvidno iz Slike 1, so med vsemi vrstami diskurza najpogostejši v literarnem diskurzu (3,4 pojavitve na 1000 besed), kar verjetno odraža dejstvo, da ta vsebuje veliko dialoga (saj gre primarno za pripovedno prozo), ki je poskus imitacije govorjenega diskurza, hkrati pa je $\mathrm{v}$ dialogu $\mathrm{v}$ primerjavi $\mathrm{z}$ monologom mnogo pogostejša funkcija nagovora. $\mathrm{V}$ drugih treh vrstah diskurza se osebni zaimki kot osebki pojavljajo izrazito redko. Morda je na prvi pogled nekoliko presenetljivo, da pri tem ne izstopajo internetna besedila (1,4 pojavitve na 1000 besed) s svojo hibridno naravo: verjetno je to mogoče pripisati dejstvu, da v korpusu Kres internetni diskurz vsebuje velik delež novic na novičarskih portalih, ki so po formalnosti podobne klasičnemu medijskemu diskurzu, pregled primerov pa pokaže, da se osebni zaimki kot osebki najbolj izrazito pojavljajo $\mathrm{v}$ neformalnih spletnih komentarjih. Zastavlja se torej zanimivo vprašanje, ali bi bilo mogoče izrazitejša odstopanja opazovati v bolj specializiranem korpusu računalniško posredovane komunikacije, kakršen je Janes (Fišer in dr. 2017). V tiskani periodiki in strokovnem diskurzu zelo redka raba osebnih zaimkov kot osebkov (v obeh 
primerih je pogostost 0,9 pojavitve na 1000 besed) nikakor ne preseneča, glede na to, da gre za zelo formalni vrsti diskurza.

\subsection{Funkcijska analiza rabe osebnih zaimkov kot osebkov}

Glede na izrazito korelacijo med pogostostjo rabe osebnih zaimkov in formalnostjo besedilnih zvrsti, predstavljeno v 4.1., bi na prvi pogled lahko pričakovali, da se (ne)izražanje osebnega zaimka neposredno navezuje na žanrske konvencije in jo je mogoče z njimi preprosto pojasniti. Natančnejša funkcijska analiza pokaže, da gre za mnogo kompleksnejši pojav, na katerega vpliva preplet različnih dejavnikov. Neposredna, enoznačna navezava razlage na žanrske konvencije, bi predstavljala poenostavitev realnosti, hkrati pa bi tak pristop predstavljal odmik od namena korpusne raziskave, ki je v prvi vrsti popisati dejansko stanje v jeziku.

Funkcijska analiza je potrdila, da je v skladu z literaturo (prim. npr. Rothman 2009, Pisanski Peterlin in Mikolič Južnič 2018) smiselno te elemente razdeliti na dve širši, osnovni funkciji, in sicer na razdvoumljanje in poudarjanje, $\mathrm{v}$ okviru vsake od njih pa je mogoče identificirati različne diskurzno-pragmatične dejavnike, ki vplivajo na rabo osebnih zaimkov kot osebkov. V nadaljevanju sta podrobneje opisani obe funkciji, znotraj vsake pa so predstavljeni posamezni diskurzno-pragmatični dejavniki z ilustrativnimi primeri rabe iz analiziranih korpusov Kres in Gos; za vsak primer je naveden tako korpus kot podkorpus. Na koncu so strnjena še nekatera druga opažanja v zvezi z rabo osebnih zaimkov kot osebkov.

\section{Razdvoumljanje}

O razdvoumljanju govorimo, kadar identiteta vršilca dejanja v slovnični funkciji osebka ni jasna, zato mora biti ta eksplicitno izražen, da se referenčna nejasnost razdvoumi. V analiziranem korpusu se funkcija razdvoumljanje pojavlja iz različnih vzrokov, ki se navezujejo na različne ravni jezika. 


\subsection{Oblikoslovna raven: Osebek ni razviden iz glagolske oblike}

V nekaterih primerih razlogi za uporabo osebnega zaimka kot osebka izvirajo iz povsem oblikoslovnih razlogov. $\mathrm{V}$ teh primerih je eksplicitno izražen osebek nujen, ker ni nedvoumno razviden iz glagolske oblike.

\subsubsection{Elipsa glagola}

Za razdvoumljanje je uporaba osebnega zaimka kot osebka nujna ob elipsi glagola. V primeru (1), ki je del športnega komentarja, je glagol (npr. smučati v smislu »ona pa smuča z napako «) opuščen, brez osebka bi bilo »pa z napako« nemogoče smiselno interpretirati.

(1) menjavam eee smeri ///[1 premor][prazen] ///ja tu nekoliko lažji prehod/ona pa z napako/zavrtelojojev samem vhoduv (GOS Javni razvedrilni diskurz)

\subsubsection{Oblikoslovna nejasnost}

Prav tako je osebek nujen v stavkih, kjer prihaja do oblikoslovne nejasnosti, ker so glagolske oblike enake za različne osebe (npr. pogojnik ali druga in tretja oseba dvojine).

(2) veš on bi nam lahko povedaljaz bi pa kakšno parcelo kupila (GOS Nejavni nezasebni diskurz)

(3) njenim vrhom božati dlan. "Vem, da nista vedve sprožili predaje, mislim, da celo Harold to ve (KRES Leposlovje)

(4) ob tem pa nihče ne omenja, da sta onadva v finalu zbrala čez trideset tisoč glasov in konkurentke pustila (KRES Periodika)

\subsection{Skladenjska raven}

Uporaba osebnega zaimka kot osebka je $\mathrm{v}$ nekaterih primerih pogojena $\mathrm{s}$ skladenjskimi vzorci. 


\subsubsection{Priredni osebek}

Kadar je osebek sestavljen iz priredno vezanih elementov, so ti elementi izraženi kot samostalniki ali zaimki.

(5) Ona in brata in sestre so vsi že odrasli; mati. (KRES Strokovna besedila)

\subsection{2 $\underline{\mathrm{S} \text { povedkovim določilom }}$}

Prav tako je uporaba osebnega zaimka nujna v stavkih s povedkovim določilom, v katerih je izražena identičnost med osebkom in povedkovim določilom, saj bi bili sicer takšni stavki nesmiselni.

(6) če se ji tako zahoče. Ker ona je ona. (KRES Periodika)

\subsection{Diskurzna raven: Členitev po aktualnosti}

V kontekstih, kjer se zamenja tema, je za smiselno interpretacijo nujen eksplicitno izražen osebek: kadar je referent novega osebka znan že od prej, je osebni zaimek eden od elementov, ki lahko uspešno izrazi referenta. V primeru (7) je eksplicitno izražen osebek nujen za ustrezno posredovanje želene informacije (prim. hipotetični primer (7a), ki sicer nakazuje, da je prišlo do menjave teme, vendar pragmatično ni ustrezen).

(7) Sva enakopravna. On odloča, kje bo kateri kuhal in vlagal. (KRES Periodika)

(7a) Sva enakopravna. Odloča, kje bo kateri kuhal in vlagal.

\subsubsection{Kontrast}

Zelo očitna situacija, pri kateri se tema zamenja, je vzpostavljanje kontrasta. ${ }^{8} \mathrm{~V}$ takšnih situacijah, v katerih sta vedno sopostavljena vsaj dva referenta (lahko tudi več), je osebek zaradi jasnosti eksplicitno izražen. V hipotetičnem primeru

8 Zaradi jasnosti uporabljava izraz »kontrast «, s katerim želiva opisati pragmatično funkcijo in nikakor ne nujno slovnično kategorijo protivnosti. 
(8a) nastopi potencialna pomenska nejasnost $\mathrm{v}$ kombinaciji $\mathrm{s}$ spremembo pomena.

(8) Delam, kakor se znajdem. Ona pa vidi samo denar. (KRES Periodika)

(8a) Delam, kakor se znajdem. Pa vidi samo denar.

\subsubsection{Primerjava}

Podobno kot pri kontrastu sta tudi pri primerjavi nujno prisotna dva referenta, ki se ju med seboj primerja. Hipotetični primer brez izraženega osebka elitiptičnega stavka (9a) ni mogoč, vendar ne zaradi elipse (prim. hipotetični primer (9b) brez elipse glagola, ki še vedno pragmatično neuspešen). Primerjava namreč zahteva eksplicitno poimenovanje obeh primerjanih entitet, zato sodi v kategorijo razdvoumljanja, kjer je raba eksplicitnega osebka iz pragmatičnih razlogov obvezna, in ne poudarjanja, kjer je možna, ne pa nujna.

(9) Tudi ona je naša gostja, tako kot vi, «je (KRES Leposlovje)

(9a) Tudi ona je naša gostja, tako kot, «je

(9b) Tudi ona je naša gostja, tako kot ste, «je

\subsubsection{Prehod iz reme v temo}

V nekaterih primerih pri razdvoumljanju lahko opazujemo prehod iz reme v temo.

(10) slabo spoznam za to imamo dobro plačane ljudi in naj oni razmišljajo o tem. (KRES Periodika)

\subsection{Raven prenosnika: Netekočnosti v spontanem govoru}

Pri opisu razdvoumljanja je treba posebej opozoriti na to, da se v spontanem govoru iz očitnih razlogov (napačni začetki, popravljanja, ponavljanja, hkratni govor) pogosto pojavlja dodatna potreba po razdvoumljanju.

(11) odgovoriš na na tisti /// aha / ja ma saj sem ji /// ona je si rekla 
daje poslala na konferenčni naslov a (GOS Nejavni nezasebni diskurz)

\section{Poudarjanje}

O poudarjanju govorimo, kadar je identiteta osebka sicer nedvoumna in jasna, vendar se osebek vseeno izrazi z namenom, da se referent poudari.

(12) Pride dan, ko bi komu rekel: tudi jaz sem samo človek, tudi jaz imam kup problemov. (KRES Periodika)

Pogosto se poleg zaimka uporabi še kakšno drugo sredstvo za poudarjanje, kot tudi v primeru (12) in prav in sam v primerih (13) in (14):

(13) Seveda ob tem zavestno pozabljajo, da so bili prav oni $v$ preteklih letih nekakšni vladni zgodovinarji, ki so služili (KRES Periodika)

(14) Vidim vaju, vidim vaju; jaz sama predstavljam celo množico, množico, Garcin, množico (KRES Strokovna besedila)

\subsection{Pragmatična smiselnost: Razlika med poudarjanjem in razdvoumljanjem}

$\mathrm{V}$ tovrstnih primerih velja posebej izpostaviti dejstvo, da lahko seveda do poudarjanja pride tudi pri razdvoumljanju. Razlikovanje, ki ga uvajava $\mathrm{v}$ pričujočem prispevku, tako temelji na tem, da je pri razdvoumljanju osebek vedno obvezen, saj bi bil stavek sicer pragmatično nesmiseln, če pa gre le za poudarjanje, bi bilo osebek mogoče tudi opustiti, kot npr. v hipotetičnem primeru (14a).

(14) kako naj pa pogledam tovarišici Lidiji v oči, če ona stanuje na boljšem kot mi, in bodo rekli, (KRES Leposlovje)

(14a) kako naj pa pogledam tovarišici Lidiji $v$ oči, če stanuje na boljšem kot mi, in bodo rekli,

Poudarjanje se pogosto uporablja v primerih, kjer se tema očitno ohranja.

(15) so že prišli gasilci, prav hitri so bili, oni so ju pozneje rešili. (KRES Periodika) 


\subsection{Spontani govor}

\subsubsection{Slovnica govorjenega jezika in netekočnosti}

Kot pri razdvoumljanju velja tudi pri opisu podfunkcij poudarjanja izpostaviti dejstvo, da je raba v spontanem govoru specifična, saj je poudarjanje lahko izrazitejše, morda vezano celo na idiolekt posameznega govorca.

(16) zapacano ampak njej je uspelo tisto namazati in kako je ona bila takrat ponosna [1 delno] nase a ne / in to to (GOS Javni informativnoizobraževalni diskurz)

(17) me zanima nekaj ... kaj si ti poslušal kaj je ona prebrala ? si figo poslušal /// ne /// ja /// ti si poslušal (GOS Javni informativnoizobraževalni diskurz)

(18) že videla da ne morem se pogovarjati z njo ker ona je bila ful pijana / potem je šla noter in ven (GOS Javni informativnoizobraževalni diskurz)

\subsubsection{Nagovor v dialogu}

V spontanem govoru je poudarjanje pogosto pri nagovoru, zato je ta raba izrazito vezana na drugo osebo:

(19) ti kaj vidva študirata (GOS Nejavni zasebni diskurz)

(20) »Fanta, vidva bi že zdavnaj morala biti $v$ postelji," je9 (KRES Leposlovje)

$\mathrm{V}$ istem kontekstu se kot potencialna razlaga za rabo osebnih zaimkov kot osebkov za poudarjanje ponuja tudi možnost, da gre za dialektalno specifiko. Ugotavljanje vpliva dialektov presega okvire pričujoče raziskave, se pa postavlja

\footnotetext{
9 Navedeni primer je sicer iz Kresa, vendar iz dvogovora v literarnem besedilu, ki odraža posnemanje spontanega govora. Prav takšni primeri dokazujejo, da poenostavitve v smislu neposredne korelacije med monološkostjo proti dialoškosti in pisnim ter govorjenim diskurzom za pričujoče gradivo niso smiselne.
} 
kot zanimiva možnost za nadaljnje študije na tem področju.

(21) je rekla je prišla punčka domov cela žalostna zato ker ona ne sme gledati eee mislim da Sosedovi ali neke oddaje (GOS Javni informativno-izobraževalni diskurz)

\section{Druga opažanja}

Primeri, v katerih se osebni zaimki navezujejo na nežive in kolektivne referente, so sicer redki, vendar se pojavljajo.

(22) Kar pa se tiče bančnih računalnikov, so seveda tudi oni ravno tako ranljivi kot vsi drugi računalniški sistemi (KRES Leposlovje)

(23) vodstvo odgovorno za proces proti četverici in da ga je ono tudi insceniralo, za političen konstrukt, zgrajen na neresnicah (KRES Periodika)

\section{SKLEP}

Namen raziskave je bil na podlagi korpusne analize razčleniti rabo osebnih zaimkov $\mathrm{v}$ funkciji osebka $\mathrm{v}$ slovenščini s pragmatičnega vidika in pridobiti dodatne podatke za podrobnejši slovnični opis tega pojava, ki je bil v dosedanjih slovničnih opisih, npr. v Toporišič (2000), obravnavan manj podrobno. V spontano tvorjenih slovenskih besedilih, ki jih tvorijo rojeni govorci, se raba zaimka morda redko problematizira, po drugi strani pa predstavlja vsaj $\mathrm{v}$ prevedenih besedilih izziv za prevajalca v slovenščino (prim. Pisanski Peterlin in Mikolič Južnič 2018). Analiza, predstavljena v pričujočem prispevku, je tako pokazala, da gre pri rabi osebnega zaimka kot osebka nedvomno za mnogo kompleksnejšo slovnično problematiko, kot bi lahko sklepali iz dosedanjih opisov. Pokazalo se je tudi, da je na podlagi podatkov, pridobljenih s korpusno analizo, mogoče izdelati podroben slovnični opis rabe osebnih zaimkov v funkciji osebka v slovenščini.

Pri analizi sva izhajali iz dveh raziskovalnih vprašanj. Prvo je bilo, ali je 
pogostost rabe osebnega zaimka kot osebka pogojena $\mathrm{z}$ besedilno zvrstjo. Rezultati korpusne analize so pokazali, da je v analiziranem gradivu mogoče opazovati velike razlike $\mathrm{v}$ pogostosti rabe osebnega zaimka kot osebka med posameznimi sklopi besedil, pri čemer je raba v spontanem, zlasti dialoškem, govoru in manj formalnih besedilih izrazito pogostejša kot $\mathrm{v}$ pisnih besedilih in v bolj formalnih žanrih.

Drugo raziskovalno vprašanje je bilo, kateri dejavniki vplivajo na rabo osebnega zaimka kot osebka. Rezultati analize so identificirali vrsto dejavnikov, ki v različni meri vplivajo na rabo osebnega zaimka kot osebka. V najširšem smislu bi lahko rekli, da je tudi za slovenščino, podobno, kot je že bilo predlagano za druge jezike s opustljivim osebkom (glej npr. argumentacijo v Rothman 2009), mogoče rabo zaimkov ugotavljati $v$ funkcijah razdvoumljanja in poudarjanja. Podrobnejša funkcijska analiza pa je pokazala, da so pri razdvoumljanju v ospredju dejavniki, ki se navezujejo na uvajanje nove teme, različne vrste primerjav ali protistavljanja, priredno vezane osebke in oblikoslovne nejasnosti. Pri poudarjanju se osebni zaimek kot osebek pojavlja v kontekstih, v katerih se tema ohranja. Tako pri razdvoumljanju kot pri poudarjanju se osebni zaimek kot osebek pogosto pojavi v spontanem govoru, kar je posledica specifike dialoškosti (nagovor) in netekočnosti.

Pričujoča raziskava je potrdila, da je korpusni pristop pomemben za pridobivanje podatkov za slovnično-pragmatične opise. Hkrati rezultati, ki zelo jasno kažejo postopno upadanje pogostosti rabe osebnih zaimkov kot osebkov z naraščanjem formalnosti, potrjujejo, da je žanrska zasnova korpusov Kres in Gos za tovrstne slovnične opise nadvse primerna.

Rezultati odpirajo nekatera zanimiva vprašanja, ki bi lahko bila izhodišče za nadaljnje raziskave. Tako se postavlja vprašanje dialektalnega vpliva na rabo zaimkov v vlogi osebka, saj rezultati korpusa Gos identificirajo nekatere rabe, ki bi lahko bile specifične za posamezne dialekte, vendar bi za natančnejše sklepanje o tem potrebovali drugačen nabor podatkov. 
Drugo vprašanje, ki bi ga veljalo razjasniti, je, kakšno je stanje na področju internetnega diskurza: rezultati pričujoče študije kažejo, da je osebni zaimek kot osebek v internetnih besedilih najpogosteje prisoten v spontano tvorjenih, neformalnih komentarjih. Če bi se tovrstne raziskave lotevali s korpusnega vidika, bi lahko predstavljala analiza specializiranega korpusa računalniško posredovane komunikacije, kakršen je Janes, zanimivo nadgradnjo pričujoče študije.

Tretje vprašanje, ki izhaja iz pridobljenih rezultatov, pa se navezuje na rabo osebnega zaimka kot osebka $\mathrm{v}$ slovenščini v primerjavi $\mathrm{z}$ drugimi jeziki $\mathrm{z}$ opustljivim osebkom. Dobljeni podatki potrjujejo, da so funkcije osebnega zaimka kot osebka v slovenščini funkcijsko podobne kot v nekaterih drugih jezikih z opustljivim osebkom, (španščina, italijanščina), v katerih so bile tovrstne funkcije že podrobneje razčlenjene. Tako se postavlja vprašanje, čemu je torej mogoče pripisati velike razlike $\mathrm{v}$ pogostosti rabe, ki so bile zaznane $\mathrm{v}$ predhodni kontrastivni raziskavi (Pisanski Peterlin in Mikolič Južnič 2018). Nekaj dodatnih podatkov $\mathrm{v}$ zvezi $\mathrm{s}$ tem bi morda lahko pridobili tudi $\mathrm{z}$ neposredno primerjavo slovenščine s sorodnimi, slovanskimi jeziki, čeprav je na podlagi novejših klasifikacij jezikov $\mathrm{z}$ opustljivim osebkom mogoče ugotavljati, da sorodstvena razmerja med jeziki niso nujno ključni dejavnik za iskanje podobnosti med njimi pri vprašanju opustljivega osebka. Tako npr. Roberts in Holmberg (2010: 11) navajata, da je celo med evropsko in brazilsko portugalščino mogoče opazovati velike razlike: medtem ko je evropska portugalščina, enako kot slovenščina, jezik $\mathrm{s}$ konsistentno opustljivim osebkom, se brazilska portugalščina, podobno kot ruščina, uvršča med jezike z delno opustljivim osebkom. Morda je odgovor v zvezi s specifiko slovenščine vsaj delno mogoče iskati v opažanju, da v slovenščini pogostost rabe osebnega zaimka kot osebka upada $\mathrm{z}$ naraščanjem formalnosti, vendar bi bilo za bolj podkrepljeno sklepanje o tem treba izvesti raziskavo o lektorskih posegih $\mathrm{v}$ osebne zaimke kot osebke; če bi bila raziskava te tematike korpusne narave, bi lahko bila narejena na korpusu Lektor. Drugo možnost za nadaljnje iskanje 
odgovorov predstavlja raziskava opismenjevanja oziroma usvajanja pisnega standarda, ki bi pokazala, ali je mogoče opazovati vzporednice med dolžino šolanja in upadom rabe zaimkov v pisnih besedilih šolarjev, kar je mogoče raziskovati z različnimi metodami, vključno s korpusno (npr. na korpusu Šolar).

\section{ZAHVALA}

Članek je nastal v okviru programskega financiranja ARRS. Raziskovalna programa št. P6-0215 in P6-0218 je sofinancirala Javna agencija za raziskovalno dejavnost Republike Slovenije iz državnega proračuna.

\section{LITERATURA}

Baroni, M., in Bernardini, S., (2006): A new approach to the study of translationese: Machine-learning the difference between original and translated text. Literary and Linguistic Computing, 21 (3): 259-274.

Chomsky, N., (1981/1988): Lectures on Government and Binding: the Pisa Lecture. 5th Edition. Dordrecht/Providence: Floris Publications.

Conrad, S., (2010): What can a corpus tell us about grammar. V O'Keefe, Anne in Michael McCarthy (ur.): Routledge Handbook of Corpus Linguistics 227-240. London in New York: Routledge.

Crystal, D., (1994): An Encyclopedic Dictionary of Language and Languages. London: Penguin.

de Prada Pérez, A., (2009): Subject Expression in Minorcan Spanish: Consequences of Contact with Catalan. Doktorska disertacija. The Pennsylvania State University.

Fišer, D., Erjavec, T., in Ljubešić, N., (2017): The compilation, processing and analysis of the Janes corpus of Slovene user-generated content. V Wigham, C.R. in G. Ledegen (ur.): Corpus de communication médiée par les réseaux: construction, structuration, analyse. Collection Humanités Numériques. Paris: L’Harmattan. 
Golden, M., (2001): O jeziku in jezikoslovju. Ljubljana: Filozofska Fakulteta Univerze v Ljubljani, Oddelek za Primerjalno in splošno jezikoslovje.

Gorjanc, V., (1999): Kohezivni vzorec matematičnih besedil. Slavistična revija, 47 (2): 139-159.

Hyland, K., in Paltridge, B., (2011): Introduction. V Hyland, K. in B. Paltridge (ur.): The Continuum Companion to Discourse Analysis 1-5. London in New York: Continuum.

Jaeggli, O., in Safir, K., (ur.), (1989): The Null Subject Parameter. (Studies in Natural Language and Linguistic Theory). Dordercht: Kluwer.

Koletnik, M., (2008): Prekmursko narečje v medijih. Pezdirc Bartol, M. (ur.): Slovenski jezik, literatura, kultura in mediji. 44. seminar slovenskega jezika, literature in kulture 36-42. Ljubljana: Filozofska fakulteta, Oddelek za slovenistiko, Center za slovenščino kot drugi/tuji jezik.

Korošec, T., (1981): Besediloslovna vprašanja slovenščine. XVII. seminar slovenskega jezika, literature in kulture. Ljubljana: FF. 173-186.

Korpus Gos - spletni konkordančnik. Dostopno prek: http://www.korpus-gos.net/. (Datum dostopa: 26. 12. 2017.)

Korpus Kres - spletni konkordančnik. Dostopno prek: http://www.korpuskres.net/. (Datum dostopa: 26. 12. 2017.)

Krek, S., (2013): Korpusne metode in njihov odsev v jezikoslovnih teorijah 20. stoletja. Slovenščina 2.o., 1 (1): 4-23.

Logar Berginc, N., Grčar, M., Brakus, M., Erjavec, T., Arhar Holdt, Š., in Krek, S., (2012). Korpusi slovenskega jezika Gigafida, KRES, ccGigafida in ccKRES: gradnja, vsebina, uporaba. Ljubljana: Trojina, zavod za uporabno slovenistiko; Fakulteta za družbene vede.

Mauranen, A., (2005): Contrasting languages and varieties with translational corpora Languages in Contrast, 5 (1): 73-92. 
NoSketch Engine. Dostopno prek: http://nl.ijs.si/noske/index.html. (Datum dostopa 26. 12. 2017.)

Paradis, J., in Navarro, S., (2003): Subject realization and crosslinguistic interference in the bilingual acquisition of Spanish and English: What is the role of the input? Journal of Child Language, 30 (2): 371-393.

Perlmutter, D., (1968): Deep and Surface Structure Constraints in Syntax. Doktorska disertacija. Cambridge, MA: Massachussets Institute of Technology.

Pisanski Peterlin, A., in Mikolič Južnič, T., (2018): Contrasting pronominal subjects: A cross-linguistic corpus study of English, Italian and Slovene. Languages in Contrast, 18 (2): 230-251.

Posio, P., (2012): Who are 'we' in spoken Peninsular person plural subjects. Language Sciences, 34 (3): 339-360.

Roberts, I., in Holmberg, A., (2009): Introduction: parameters in minimalist theory. V Biberauer, T., Holmberg, A., Roberts, I., in Sheehan, M., (ur.): Parametric Variation: Null Subjects in Minimalist Theory 1-57. Cambridge: Cambridge University Press.

Rothman, J., (2009): Pragmatic deficits with syntactic consequences? L2 pronominal subjects and the syntax-pragmatics interface. Journal of Pragmatics, 41 (5): 951-973.

Serratrice, L., (2007): Referential cohesion in the narratives of bilingual English-Italian children and monolingual peers. Journal of Pragmatics, 39 (6): 1058-1087.

Sorace, A., in Filiaci, F., (2006): Anaphora resolution in near-native speakers of Italian. Second Language Research, 22 (3): 339-368.

Sporazumevanje v slovenskem jeziku - spletni portal. Dostopno prek:

http://www.slovenscina.eu/. (Datum dostopa 26. 12. 2017.) 
Toporišič, J., (2004): Slovenska slovnica. 4. izdaja. (1. izdaja 1976). Maribor: Obzorja.

Travis, C. E., (2007): Genre effects on subject expression in Spanish: Priming in narrative and conversation. Language Variation and Change, 19 (2): 101-135.

Tsimpli, I., Sorace, A., Heycock, C., in Filiaci, F., (2004): First language attrition and syntactic subjects: A study of Greek and Italian nearnative speakers of English. International Journal of Bilingualism, 8 (3): $257-277$.

Verdonik, D., in Zwitter Vitez, A., (2011): Slovenski govorni korpus Gos. Ljubljana: Trojina, Zavod za uporabno slovenistiko.

Verdonik, D., Kosem, I., Zwitter Vitez, A., Krek, S., in Stabej, M., (2013): Compilation, transcription and usage of a reference speech corpus: the case of the Slovene corpus GOS. Language Resources and Evaluation, 47 (4): 1031-1048. 


\section{SUBJECT PERSONAL PRONOUNS IN SLOVENE: PRAGMATIC ASPECTS OF A GRAMMATICAL CATEGORY}

Corpus analysis can yield relevant data on a range of grammatical features; this data can be used to produce in-depth descriptions of grammar. Corpus methodology is particularly useful for grammar research focusing on pragmatics and variation in the use of selected grammatical features. The present study aims to analyse the use of subject personal pronouns in Slovene from a pragmatic point of view in order to obtain new data for a more detailed description of the use of subject personal pronouns in Slovene. Slovene is a null-subject language; this means that it does not require the explicit expression of the subject of the clause. The study is based on corpus analysis of the Kres and Gos corpora; NoSketch Engine, Web-based text-analysis software, was used in the analysis. The results identify a considerable difference between the frequencies of subject personal pronouns in spoken discourse as opposed to written discourse. The results also show that the frequency of subject personal pronouns decreases with an increase in formality. Functional analysis reveals that overt subject personal pronouns can be classified broadly into two main categories, disambiguation and emphasis. In the category of disambiguation, the use of subject personal pronouns is influenced by morphological, syntactic and discursive factors, as well as the medium of communication. In the category of disambiguation, the medium of communication is a particularly relevant factor. The analysis shows that the use of subject personal pronouns in Slovene is far more complex than previous descriptions suggest. The findings raise interesting questions regarding the use of subject personal pronouns in Slovene in terms of dialects and hybrid Internet genres, as well as questions relating to editorial interventions and the impact of literacy development.

Keywords: subject personal pronoun, null-subject language, corpus analysis 
To delo je ponujeno pod licenco Creative Commons: Priznanje avtorstvaDeljenje pod enakimi pogoji 4.o Mednarodna.

This work is licensed under the Creative Commons Attribution-ShareAlike 4.0 International.

https://creativecommons.org/licenses/by-sa/4.0/

(C) (1) () 